\title{
Sleep apnoea, hypertension and vascular disease: where are we now?
}

\author{
B. Buyse*, J. Hedner ${ }^{\#}$ and the participants of working group 2 ?
}

\begin{abstract}
The objective of the present article was to explore the relationship between obstructive sleep apnoea (OSA) and hypertension (HT) and/or arterial vascular disease (VD), including stroke and ischaemic coronary disease.

Epidemiological and interventional studies on these relationships provide compelling evidence that OSA is causally related to HT. The causal relationship between OSA and VD other than HT has not been firmly established.
\end{abstract}

A number of pathophysiological mechanisms that could potentially provide a causal link between obstructive sleep apnoea and hypertension, as well as vascular disease, have been identified. Available data on such mechanisms include sustained daytime sympathetic activation, oxidative stress, promotion of vascular inflammation and endothelial dysfunction.

KEYWORDS: Free radicals, hypertension, inflammation, sleep apnoea, sympathetic, vascular disease

$\mathrm{T}$ he objective of the present article is to explore the relationship between obstructive sleep apnoea (OSA) and hypertension (HT) and/or arterial vascular disease (VD). The relationship between OSA and cardiac failure will not be addressed, nor will the link between OSA and mortality; these topics will be addressed in other articles [1, 2] in the current issue of the European Respiratory Review (ERR). The first section of the present article will deal with clinical epidemiological and intervention data on the relationship between OSA and HT/ VD. The second section deals with the biological plausibility of the association in more detail and will discuss some important recent research papers in the area.

\section{OSA IS AN INDEPENDENT AND MODIFIABLE RISK FACTOR FOR HT/VD: CLINICAL DATA}

A large number of studies have shown that OSA is over-represented in patients with HT/VD. Conversely, the prevalence of HT/VD is higher than expected in patients with OSA; however, the establishment of OSA as an independent risk factor for HT/VD has been a challenge, as obesity is a risk factor for both OSA and HT/VD.

In order to quantify the influence of concomitant obesity in OSA-induced HT and VD, large crosssectional and longitudinal epidemiological studies are needed that adequately control for obesity. Such studies are currently available, but it is worth noting that, reciprocally; "obesity researchers have largely ignored the possibility that results attributed to obesity may be due to OSA" [3].

Other studies have established the OSA-HT association by administration of CPAP to mitigate OSA and thereby to induce changes in HT and VD. Randomised, controlled interventional trials (RCTs) using these approaches will be reviewed.

\section{Substantial literature exists suggesting that OSA contributes to systemic hypertension}

Several large cross-sectional studies, most importantly the Sleep Heart Health Study [4] and the Wisconsin Sleep Cohort Study [5] have provided strong evidence that OSA is an independent risk for HT.

The Sleep Heart Health Study [4], which enrolled $>6,000$ individuals (all subjects were $\geqslant 40$ yrs old and $47 \%$ of the subjects were $>65$ yrs old) undergoing an unattended home polysomnography, identified an independent association between OSA and HT. Although the impact of OSA on hypertension was modest, there was a dose dependency, as the HT prevalence increased along with an increased severity of OSA. The adjusted odds ratio (OR) was 1.37 for patients with an apnoea/hypopnoea index $\geqslant 30$ events $\cdot h^{-1}$ compared with those without apnoea problems (fig. 1). The Wisconsin Sleep Cohort Study [5], a cross-sectional study of $>1,000$ patients (including a younger population,

\section{AFFILIATIONS}

*Dept of Pulmonology, Centre for Sleep Monitoring and Home Ventilation, University Hospital Gasthuisberg Leuven, Belgium. " Sleep Laboratory, Pulmonary Medicine, Sahlgrenska University Hospital Gothenburg, Sweden.

"Participants of working group 2 are listed in the Appendix.

\section{CORRESPONDENCE}

B. Buyse

Dept of Pulmonology University Hospital Gasthuisberg Herestraat 49 3000 Leuven, Belgium. Fax: 3216346803 E-mail: Bertien.Buyse@ uz.kuleuven.ac.be STATEMENT OF INTEREST See Appendix 
mean age $46 \pm 8$ yrs) undergoing an in-laboratory polysomnography, revealed an even stronger adjusted OR of 3.1 (fig. 1) [5].

a)

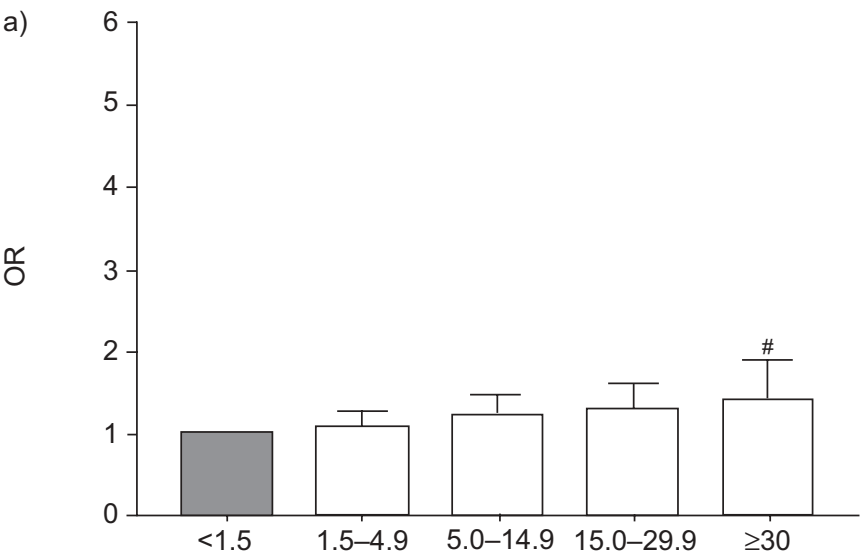

b)
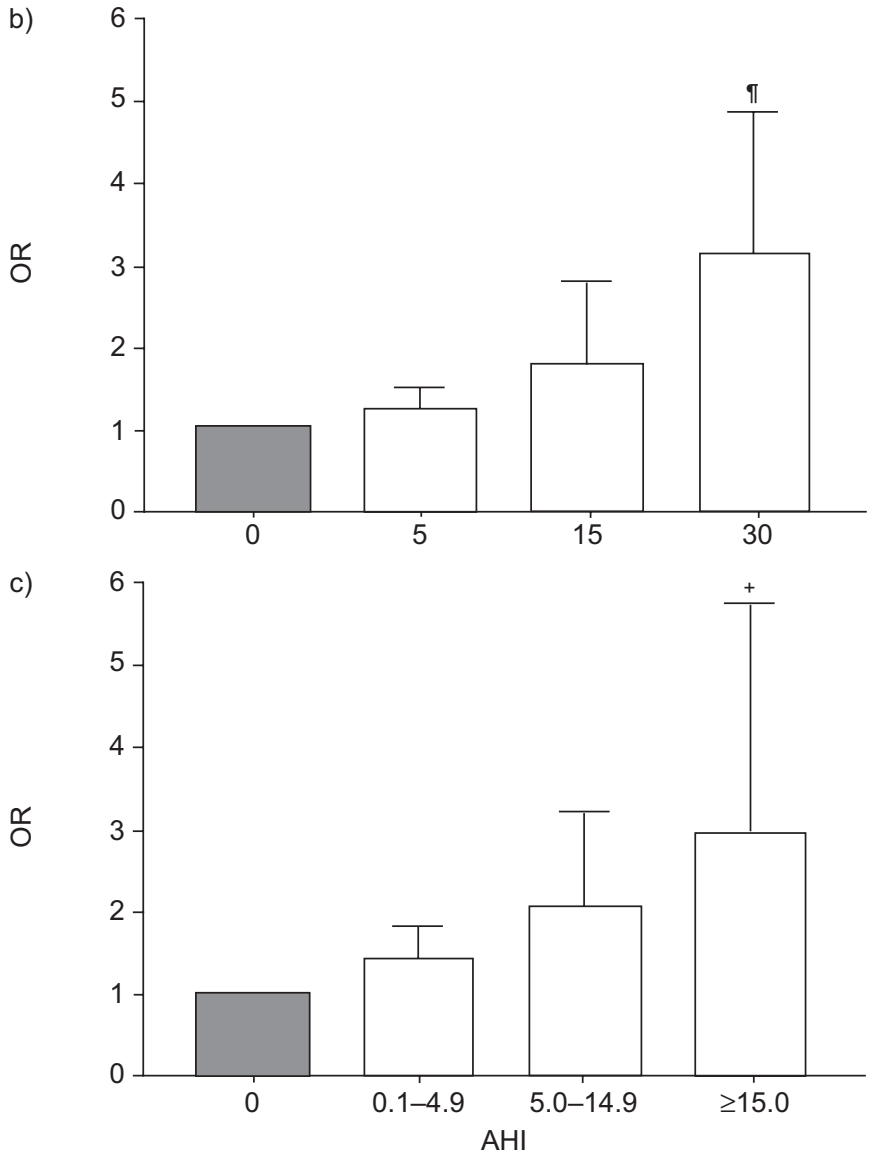

FIGURE 1. Fully adjusted odds ratio (OR; relative risk) for hypertension compared with the reference group ( $\square$ ) for a) the Sleep Heart Health Study ( $n=6,132$; cross-sectional data) [4], b) the Wisconsin Sleep Cohort Study ( $n=1,060$; cross-sectional data) [5], and c) the Wisconsin Sleep Cohort Study ( $n=893$; prospective data) [6]. Data were fully adjusted, i.e. the OR was adjusted for confounders (age, sex, body mass index, neck and waist circumference, alcohol, tobacco use and, in the case of the prospective study, baseline hypertension status). The OR and the upper $95 \%$ confidence intervals are shown. AHI: apnoea/ hypopnoea index. ${ }^{*}: \mathrm{OR}=1.37 ;{ }^{\bullet}: \mathrm{OR}=3.1{ }^{+}{ }^{+}: \mathrm{OR}=2.89$. The $\mathrm{p}$-value for trend is significant in all three studies. Data taken from [4-6].
More compelling evidence that OSA is causally related to HT is provided by the prospective longitudinal follow-up of almost 900 subjects in the Wisconsin Sleep Cohort Study [6]. The study reported an intensity related association between the apnoea severity at baseline and the development of HT during the $4 \mathrm{yr}$ follow-up period (fig. 1).

In view of the above-proven strong association between OSA and HT, a substantial blood pressure (BP) reduction would be expected with effective treatment of OSA. In addition, interventional study findings by BROOKS et al. [7] in a dog model suggest that continuous positive airway pressure (CPAP) treatment induced an obvious lowering of BP within the short term. In this model of sleep apnoea (using an ingenious methodology that involves an electronic valve intermittently occluding the trachea during the night), the dogs not only developed diurnal HT after 3-5 weeks of simulated apnoeas, but BP was also normalised within some weeks after cessation of nocturnal apnoeic breathing (fig. 2) [7].

At a first glance, the results of the RCTs of CPAP in OSA appear to be disappointing and demonstrate conflicting results. So far, 12 RCTs have been published (table 1) [8-19]. While there was no significant drop in BP with CPAP in seven studies $[8-11,13,18,19]$, there was a small decrease in 24-h diastolic BP by $1.5 \mathrm{mmHg}$ in one study [12]. Only four studies demonstrated a significant reduction of BP with an effect size ranging -3- $-10 \mathrm{mmHg}$ [14-17]. What is the explanation for these discrepant results? Few studies included a proper statistical power analysis; moreover, the number of patients treated was small and the study populations were quite heterogeneous (table 1).

An important difference between hitherto published studies is the number of hypertensive patients included. It is evident that a marked BP decrease cannot be expected with treatment in patients who do not exhibit a substantial increased BP at baseline. Indeed, some of the RCTs not only included patients with obvious elevation of $\mathrm{BP}$ at baseline, but also normotensive patients, as well as patients with normalised BP as a result of antihypertensive drug treatment. Only five RCTs stated the

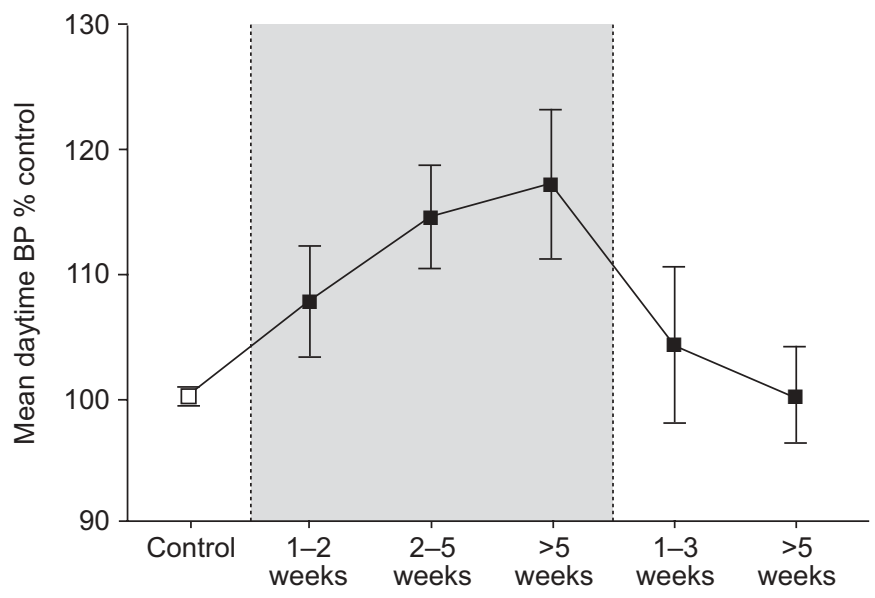

FIGURE 2. Effect of obstructive sleep apnoea on daytime blood pressure (BP) in a dog model. $1: 50-60$ apnoeas $\cdot h^{-1}$ of sleep. Modified from [7] with permission from the publishers. 


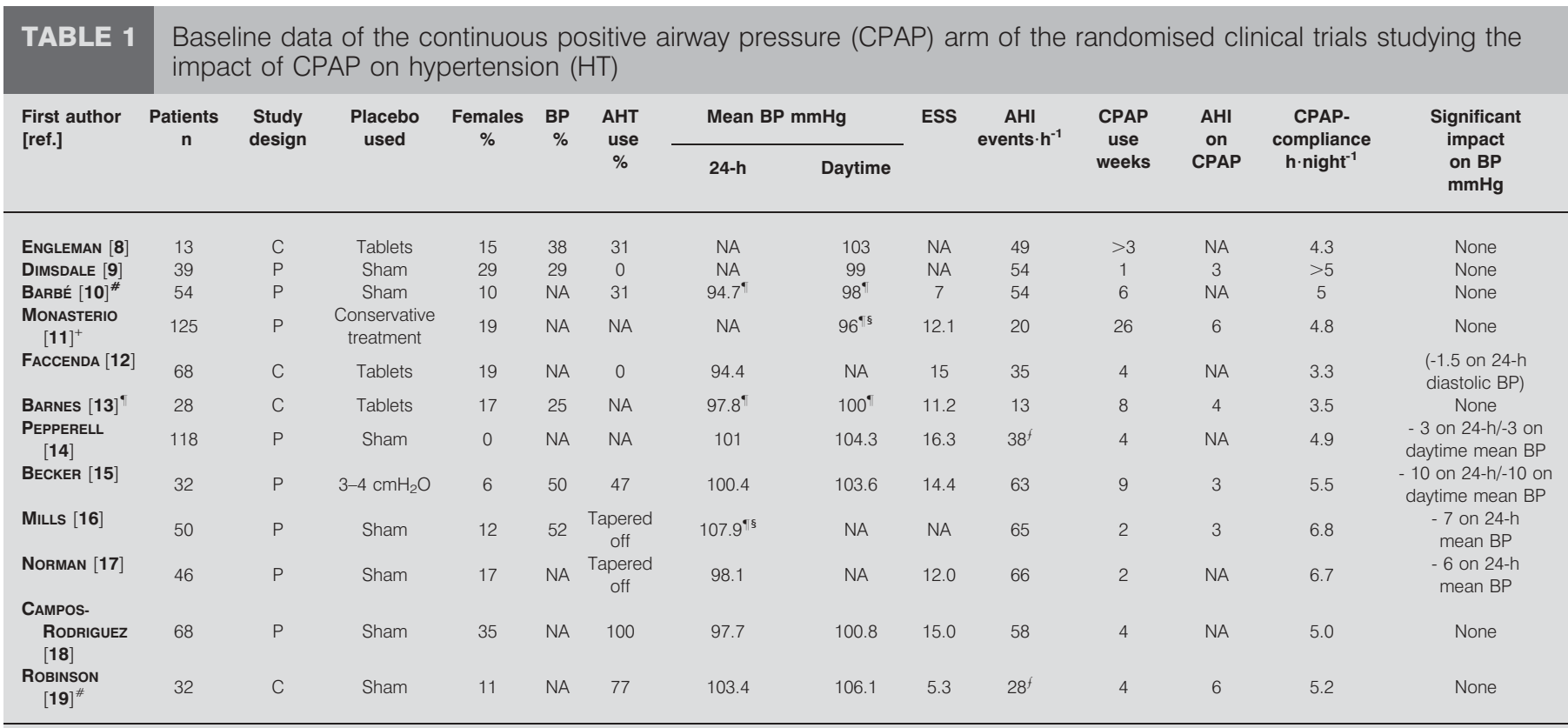

BP: blood pressure; $\mathrm{AHT}$ : antihypertensive drugs; ESS: Epworth sleepiness scale; $\mathrm{AHI}$ : apnoea/hypopnoea index; $\mathrm{C}$ : crossover; $\mathrm{P}$ : parallel; sham: sham $\mathrm{CPAP}$ delivering a pressure <2 cmH $\mathrm{O}_{2} \mathrm{O} \mathrm{NA}$ not available. ${ }^{\#}$ : studies focusing especially on patients without sleepiness; ${ }^{+}$: studies focusing especially on patients with mild increase in AHI; ${ }^{\bullet}$ calculated value $=($ systolic value $+2 \times$ diastolic value) $/ 3 ;^{\text {s: }}$ not a $24-\mathrm{h}$ ambulatory value but an office-measured value; $3-4 \mathrm{cmH}_{2} \mathrm{O} ;{ }^{f}$ : the authors used the oxygen desaturation index $\leqslant 4 \%$ instead of the $\mathrm{AHI}$. $1 \mathrm{cmH} \mathrm{H}_{2} \mathrm{O}=0.1 \mathrm{kPa}$.

exact number of patients demonstrating an increased BP at baseline $[8,9,13,15,16]$. The studies that showed the largest BP impact $[15,16]$ included at least $50 \%$ hypertensive subjects in their patient population. This is in contrast with the studies showing no or a smaller effect $[8,9,13]$.

When accounting for all studies published so far, it is evident that the severity of OSA varies considerably. The treatment effect on BP seems to be more pronounced in severe sleep apnoea. Indeed, the severity of OSA was the highest in the study by BECKER et al. [15] and in the studies by MiLLS et al. [16] and NORMAN et al. [17], which were the studies that also reported the strongest effect on BP. A subgroup analysis in two other studies also demonstrated a more pronounced reduction in BP in the patients with more severe OSA $[12,14]$. Moreover, studies specifically targeting mild-to-moderate apnoea showed no response in $\mathrm{BP}[11,13]$. It is noteworthy that these findings contrast with those of the cross-sectional and noninterventional, longitudinal follow-up studies discussed above, showing a statistically significant relationship between HT and even mild-to-moderate OSA.

CPAP compliance and efficacy should also be taken into account. A subgroup analysis clearly demonstrated that only patients who report a mean of $>5 \mathrm{~h}$ of CPAP use per night appeared to benefit in terms of BP reduction [14]. Indeed, in the other three studies proving the benefit of CPAP on BP, CPAP use was high: 5.5-6.8 h.night ${ }^{-1}$ [15-17]. Also, in the study by BECKER et al. [15] there was no BP reduction in the partially treated group; the control arm received treatment with CPAP at a minimum setting $4 \mathrm{cmH}_{2} \mathrm{O}(0.4 \mathrm{kPa})$. Despite a reduction in an apnoea/hypopnoea index (AHI) score in the order of $50 \%$, there was no reduction in $\mathrm{BP}$, suggesting that OSA needs to be completely resolved in order to receive a beneficial effect on BP. There are additional issues that need to be discussed in these studies. In several studies published to date, the treatment period may have been too short; in one study [9], the treatment period was only 1 week. Given the fact that most studies of antihypertensive drugs use a minimum treatment period of at least 4 weeks, an immediate BP resolution after CPAP would not be expected. In addition, long-standing HT may be associated with a rearrangement of smooth vessels (vascular remodelling).

Two negative studies [10,19] focused on nonhypersomnolent patients with fairly severe OSA. Consequently, it might be speculated that in patients without symptoms, there is no effect of CPAP treatment on BP. In the study by PEPPERELL et al. [14], there was also a relationship between the number of performance lapses in the Oxford Sleep Resistance test (measuring alertness), and the magnitude of BP fall with CPAP. This relationship appeared to be partially independent of OSA severity, suggesting that the mechanisms causing sleepiness may account for some of the BP elevation in OSA.

In conclusion, a critical evaluation of currently available data in OSA suggests the following: 1) in hypertensive patients with severe OSA, there is a $\mathrm{BP}$ drop reaching $10 \mathrm{mmHg}$ with $\mathrm{CPAP}$ treatment. According to published calculations, this correlates with a reduction in the incidence of coronary disease of $37 \%$ and stroke incidence of 56\% [20]. However, adequate CPAP treatment and compliance are a conditio sine qua non in order to obtain this relevant BP lowering effect. 2) There are several unresolved questions: Why do not all hypertensive OSA patients respond with $\mathrm{BP}$ reduction after CPAP? Why does the effect of CPAP treatment appear to be absent in patients with less-severe OSA, while epidemiological studies show a relationship between mild OSA and HT? Why does the impact of CPAP on BP appear to be absent in cases where the patient is not hypersomnolent? What about the effect on females? 
Since not all hypertensive OSA patients demonstrate an adequate reduction in $\mathrm{BP}$ after the initiation of CPAP treatment, an important question remains: Which antihypertensive drug will induce the most prominent reduction in $\mathrm{BP}$ ? There are only a few small-sized trials that deal with this topic [21-24], and there appears to be no antihypertensive drug class that has repetitively demonstrated superior antihypertensive efficacy. However, a more recent study using a multiple crossover design compared five substances (enalapril, losartan, atenolol, hydrochlorothiazide and amlodipin) that represent different mechanisms of action [25]. The $\beta$-blocker atenolol appeared to induce the most pronounced reduction of BP. If it is assumed that sustained overactivity of the sympathetic nervous system plays a dominant part in the physiology of hypertension in OSA, adrenoceptor blockade might be expected to be particularly effective for BP reduction in patients with this condition. Additional clinical research is certainly needed in order to identify preferable substances for an adequate BP control in this high-risk cardiovascular patient group.

\section{Does obstructive sleep apnoea contribute to vascular diseases other than HT?}

OSA has been proposed as a risk factor for VD, but the evidence is not fully conclusive. Two major topics, stroke and ischaemic coronary disease, will also be discussed; cardiac failure and cardiovascular mortality will be reviewed elsewhere in the current issue of the ERR [1,2].

\section{Is OSA a proven independent risk factor for stroke?}

In the cross-sectional analysis of the Sleep Heart Health Study (a population with a mean age of $60 \mathrm{yrs}$ ), OSA emerged as a modest risk factor for cerebrovascular disease (fig. 3) [26]. The overall OR was 1.58 and the OR was significantly higher among subjects with sleep-disordered breathing (SDB) who had an AHI of $>11$ when a parsimonious model not adjusting for body mass index (BMI) and hypertension was used [26]. The fully adjusted OR (also taking BMI and hypertension into account) was 1.55 , that is, higher in the OSA population compared with non-OSA subjects, but not significant $(\mathrm{p}=0.06)$; however, the fully adjusted OR increased to a value of 1.8 for an AHI $>19$. ARTZ et al. [27] performed a cross-sectional detailed analysis of the Wisconsin Sleep Cohort Study data (a study population with a mean age of $47 \mathrm{yrs}$, significantly younger than the study population from the Sleep Heart Health Study [4]). The association between OSA and prevalent stroke was confirmed. Moreover, it was demonstrated that this relationship was independent of potential confounding factors, such as obesity, atrial fibrillation and even HT; the fully adjusted OR for a prevalent stroke history associated with an AHI $\geqslant 20$ events $\cdot h^{-1}$ was even more than twice the adjusted OR reported for an AHI $>19$ events $\cdot h^{-1}$ in the Sleep Heart Health Study (3.83 versus 1.80) [4]. However, both studies had a cross-sectional design and the temporal relationship between SDB and stroke could not be ascertained.

There are also prospective longitudinal studies that suggest higher OR for stroke development in patients with OSA. The 4yr follow-up data from the Wisconsin Sleep Cohort Study, published by ARTZ et al. [27], provided the first prospective epidemiological evidence to demonstrate that OSA (AHI $\geqslant 20$ events $\cdot h^{-1}$ ) is associated with an increased probability of suffering a stroke (unadjusted OR 4.31). The OR was still elevated (3.08) after adjustment for BMI, age and sex, but the difference was no longer statistically significant. YAGGI et al. [28] provided follow-up data from $>1,000$ consecutive subjects without previous cardiovascular or cerebrovascular events at baseline. An AHI $\geqslant 5$ events $\cdot h^{-1}$ (mean \pm SD $35 \pm 29$ ) was demonstrated by an attended overnight polysomnography in $68 \%$ of the population, while an AHI $<5$ events $\cdot h^{-1}$ (i.e. the reference group, mean \pm SD $2.0 \pm 1.5$ ) was found in $32 \%$. The mean duration to follow-up was 3.4 yrs. The hazard ratio for OSA was 1.97 for the composite end-point of incident stroke (including transient ischaemic attack) or death from any cause after adjustment for BMI, sex, hypertension and other confounders, including atrial fibrillation. RCTs of CPAP treatment in OSA focusing the impact on stroke incidence are still lacking.

\section{Is OSA an independent risk factor for coronary disease?}

Data linking OSA to coronary artery disease are not completely convincing. In the cross-sectional analysis of the Sleep Heart Health Study [26], OSA emerged as a modest risk factor for coronary artery disease. The OR (when using a parsimonious model that did not adjust for BMI and hypertension) was 1.27 among subjects with SDB who had an AHI of $\geqslant 11$ events $\cdot h^{-1}$ [26]. However, the fully adjusted OR (also taking BMI and HT into account) was not increased in the OSA population compared with the non-OSA subjects.

There is still a lack of large longitudinal follow-up studies and interventional RCTs of the influence of OSA on incident coronary artery disease. Several small longitudinal noninterventional and interventional studies in patients with known coronary disease demonstrate a worse outcome if OSA is present $[29,30]$. CPAP appears to have a beneficial influence [31]. The interpretation of the existing data is complicated by the fact that studies were proportionally small, correction for confounding influences was incomplete and the studies used different and sometimes complex composite end-points, such as combinations of myocardial infarction, cerebrovascular events, hospitalisation for cardiac failure and death [32].

Is OSA an independent risk factor for HT and VD: how can the available clinical data be summarised?

Based on well-designed, large, cross-sectional and longitudinal epidemiological studies (the Wisconsin Sleep Cohort Study and Sleep Heart Health Study [4-6]) OSA is a proven independent risk factor for HT. In addition, it appears that OSA is a modifiable factor, at least in the patient presenting a severe symptomatic form of OSA: treatment by CPAP can reduce mean blood pressure by $10 \mathrm{mmHg}$. There is evidence for an independent causal role of OSA in stroke: cross-sectional and longitudinal follow-up data from the Wisconsin Sleep Cohort and Sleep Heart Health Cohort [26-27] are quite convincing on this aspect. However, well-designed, randomised, interventional CPAP trials are still lacking in this field. There are some data linking OSA to coronary artery disease, but these data are preliminary.

In conclusion, data from clinical epidemiological and interventional studies provide particularly strong evidence for the association between OSA and HT. The independent causal role 

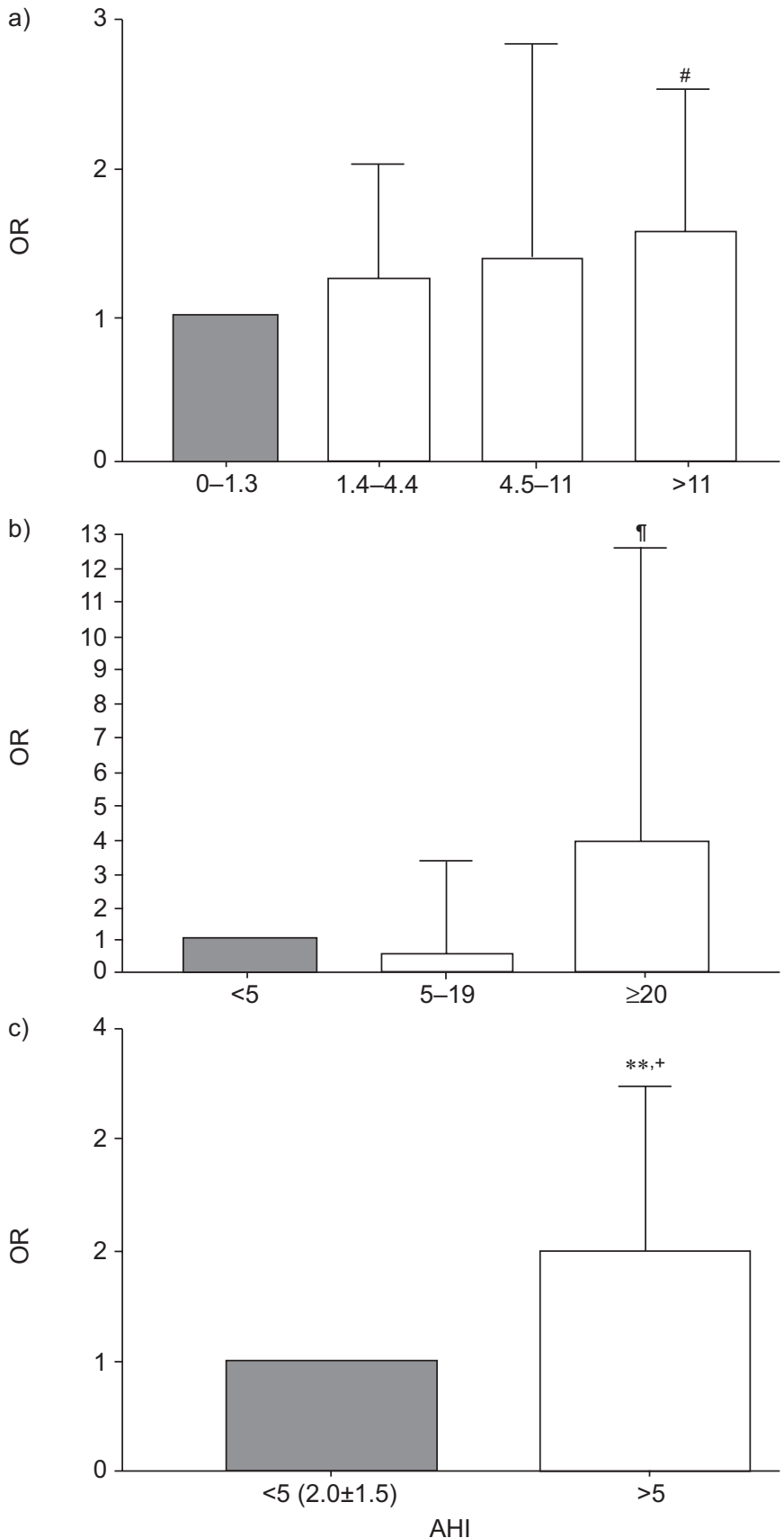

FIGURE 3. Fully adjusted odds ratio (OR; relative risk) for stroke compared with the reference group ( $\square$ ) for a) the Sleep Heart Health Study ( $n=5,250$; crosssectional data) [24], b) the Wisconsin Sleep Cohort Study ( $n=1,475$; cross-sectional data) [27], and c) the study by YAGGl et al. [28] ( $\mathrm{n}=1,022$; prospective data). Data were fully adjusted, i.e. the OR was adjusted for confounders (age, sex, body mass index, alcohol, tobacco use, diabetes, hyperlipidaemia, hypertension and, in case of the prospective study, also atrial fibrillation). The OR and the upper 95\% confidence intervals are shown. AHI: apnoea/hypopnoea index. \#: $\mathrm{OR}=1.55, \mathrm{p}=0.06$; ": $\mathrm{OR}=3.83, \mathrm{p}=0.03{ }^{+}: \mathrm{OR}=1.97 .{ }^{*}: \mathrm{p}=0.01$. Data taken from $[24,27,28]$.

for OSA in atherogenesis is less well confirmed. There is still a need for large-scale, randomised interventional trials demonstrating a reduction in cardiovascular events after CPAP treatment in OSA.
THE MECHANISMS UNDERLYING HT/VD IN OSA: WHAT IS KNOWN SO FAR?

The pathogenesis of HT/VD in OSA is incompletely understood, but is likely to be multifactorial. A range of pathophysiological mechanisms have been proposed and these have been explored in both animal and human studies. The present article will only deal with available human data that includes sustained daytime sympathetic activation, oxidative stress, activated vascular inflammatory pathways and endothelial dysfunction (fig. 4).

\section{Sustained daytime sympathetic overactivity}

Sleep apnoea episodes are associated with a pronounced increase in sympathetic activity. In 1987, FLETCHER et al. [33] had already collected urinary catecholamines before and within 2 weeks of elective tracheotomy in a small group of hypertensive subjects with severe OSA. Levels of both norepinephrine, and its metabolite normetanephrine, were significantly increased in the OSA patients compared with a control group of obese hypertensive nonapnoeic subjects. Following tracheotomy, catecholamines returned to control levels. Data supporting this finding have subsequently been published by several other groups. In a recent study of 38 patients treated with either CPAP or sham CPAP, ZIEGLER et al. [34] reported a reduction of plasma and urinary daytime catecholamine levels by nearly 26 and $36 \%$, respectively, in the treated group.

Other investigators have shown increased muscle sympathetic nerve activity (SNA) via a more direct measurement using an insertion of a tungsten microelectrode into the peroneal nerve. Using this method, HeDNER et al. [35] was the first group able to demonstrate an increase of muscle SNA following each acute event of apnoea associated with hypoxia. Several subsequent publications corroborated their findings. Of great significance was the finding that, in OSA patients, the sympathetic muscle nerve traffic was still elevated during daytime normoxic wakefulness [35-37]. In addition, it has been demonstrated that elimination of apnoeas by CPAP leads to abolishment of muscle SNA surges (and BP surges) accompanying the apnoeic events (fig. 5) [37, 38]. Even more importantly, follow-up of OSA patients has demonstrated a marked reduction of awake daytime muscle SNA at 6 months and $1 \mathrm{yr}$ after initiation of CPAP treatment (fig. 5) [39].

The exact trigger behind the sympathicoexcitation during apnoea remains uncertain. Clearly, the arousal may contribute to the acute increase in muscle SNA and BP at termination of OSA events [40]. However, there is also substantial data providing support that cyclic intermittent hypoxic episodes contribute to the activation. Asphyxia during the apnoea acutely stimulates chemoreceptors and data from OSA patients suggest that the chemoreflex activity and sympathetic activity, as well as BP surges, can be attenuated by administration of $100 \%$ oxygen $[41,42]$. Chemoreceptor stimulation acts through the central nervous system to increase sympathetic neural activity and BP increases as the apnoea progresses. During the resumption of ventilation, the restoration of venous return and consequently increased cardiac output, together with severely constricted peripheral circulation, contribute to an acute increase in BP. Once breathing resumes, sympathetic activity is instantaneously suppressed for the following two major reasons: 1) ventilation of 


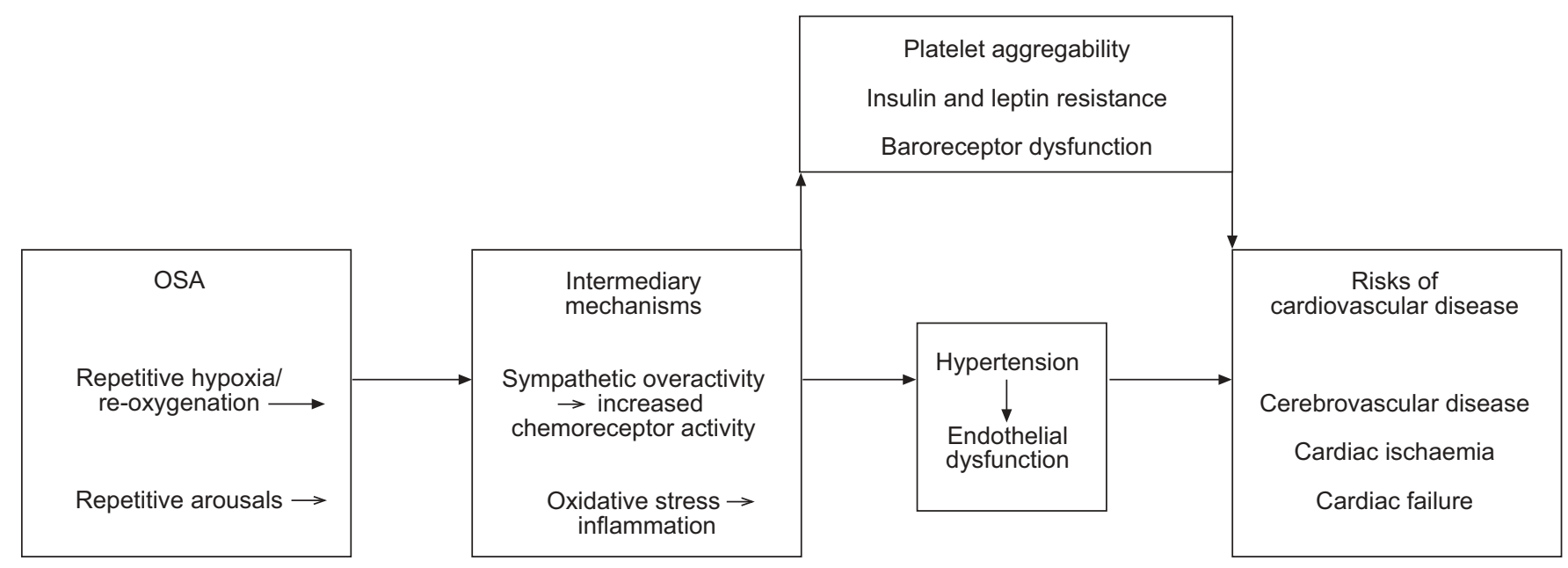

FIGURE 4. Mechanisms explaining the increased incidence of hypertension and cardiovascular disease in patients with obstructive sleep apnoea syndrome (OSA).

the lung activates vagally mediated stretch-sensitive mechanoreceptors, resulting in afferent signalling to the brainstem with sympathetic inhibition; and 2) the surge in BP activates the baroreflex to suppress sympathetic drive.

It remains unknown how this cyclic sympathetic overactivity actually leads to development of daytime HT. In a study by XIE et al. [43], a hypercapnic hypoxic gas mixture was administered intermittently (20 s of the gas mixture, $40 \mathrm{~s}$ normoxia) in healthy subjects during $20 \mathrm{~min}$. Muscle SNA was found to follow a cyclic crescendo-decrescendo pattern in conjunction with asphyxic periods. Moreover, with each successive 40-s normoxic period, muscle SNA increased progressively rather than returning to baseline (fig. 6). There are human clinical data suggesting that the peripheral chemoreflex sensitivity is augmented following exposure to cyclic intermittent hypoxia. Hypertensive subjects with OSA show an exaggerated BP response to hypoxia that was less evident in hypertensive subjects without apnoea. Collectively, this suggests that carotid chemoreceptor output may be reset to a higher level as a result of recurrent cyclic intermittent hypoxia, causing a chronic increase in sympathetic tone [44]. It has also been demonstrated that patients with OSA, besides having a heightened peripheral chemoreceptor sensitivity resulting in increased ventilation during hypoxia, also exhibit an increased chemoreceptor response during normoxia [45]. In OSA patients treated with CPAP for 3 months, there is a decrease in the ventilatory response to progressive hypoxia relative to their untreated baseline [46]. Interestingly, hyperoxia was found to decrease muscle SNA in OSA patients but not in nonapnoeic controls [42]. Sympathetic activation is also accompanied by renal sympathetic activation and thereby an activation of the renin-angiotensin-aldosterone system, including production of angiotensin II (a potent vasoconstrictor) and secretion of aldosterone (a potent salt-retention hormone), would be assumed. Activation of this cascade would be expected to result not only in increased basal arterial vascular resting tone, but also in volume overload; both factors are potential predicators of HT development.

Other studies have focussed on genetic factors as independent modulators of the physiological sympathoadrenergic response
[47]. However, the R3896 polymorphism of the $\beta 1$-adrenoceptor gene was unrelated to resting $\mathrm{BP}$ in untreated OSA patients.

\section{Oxidative stress and inflammation}

In recent years, oxidative stress has gained widespread attention as one of the fundamental mechanisms responsible for the development of cardiovascular morbidities in OSA. LAVIE [48] postulated that in OSA, hypoxia re-oxygenationrelated formation of free radicals is an early key trigger of vascular inflammation, endothelial dysfunction and atherosclerosis. One proposed schematic model is presented in fig. 7.

OSA is frequently accompanied by episodes of profound intermittent hypoxia, followed by rapid re-oxygenation. This pattern may be considered analogous to that typical of repeated reperfusion injury [49]. In response to hypoxia, the aerobic production of ATP is impaired and degradation products, such as ADP, AMP, uric acid and hypoxanthine, accumulate. As a consequence, glycolysis is upregulated and concomitantly, due to hypoxia, circulating xanthine oxidases are activated and convert xanthine dehydrogenase to xanthine oxidase. During the period of re-oxygenation, the newly activated xanthine oxidases utilise hypoxanthine and molecular oxygen to produce free radicals (fig. 7). Free oxygen radicals (which are reactive oxygen species (ROS)) are atoms or molecules possessing one or more unpaired electrons in the outer orbit. These molecules are able to react with nucleic acids, lipids and proteins, thereby potentially hindering cellular metabolism and resulting in cell injury and dysfunction. Highly reactive oxidant molecules are normally counterbalanced by antioxidants. Disturbances in the pro-oxidant versus enzymatic and nonenzymatic antioxidant system balance in favour of the former, lead to potential oxidative cell damage.

Several publications in patients with OSA have demonstrated ATP depletion with increased accumulation of ATP degradation products, such as adenosine and uric acid, and increased blood concentrations of 2,3-diphosphoglycerate, indicating that glycolysis is indeed accelerated. Moreover, several investigators demonstrated that CPAP lowered the amount 
a)

Awake

CPAP-REM

SNA

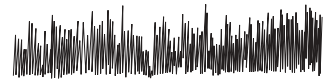

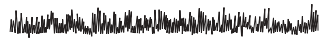

Respiration

BP

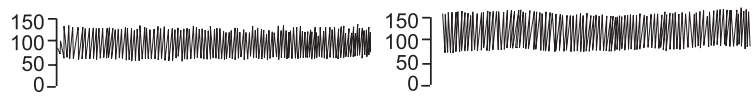

SNA
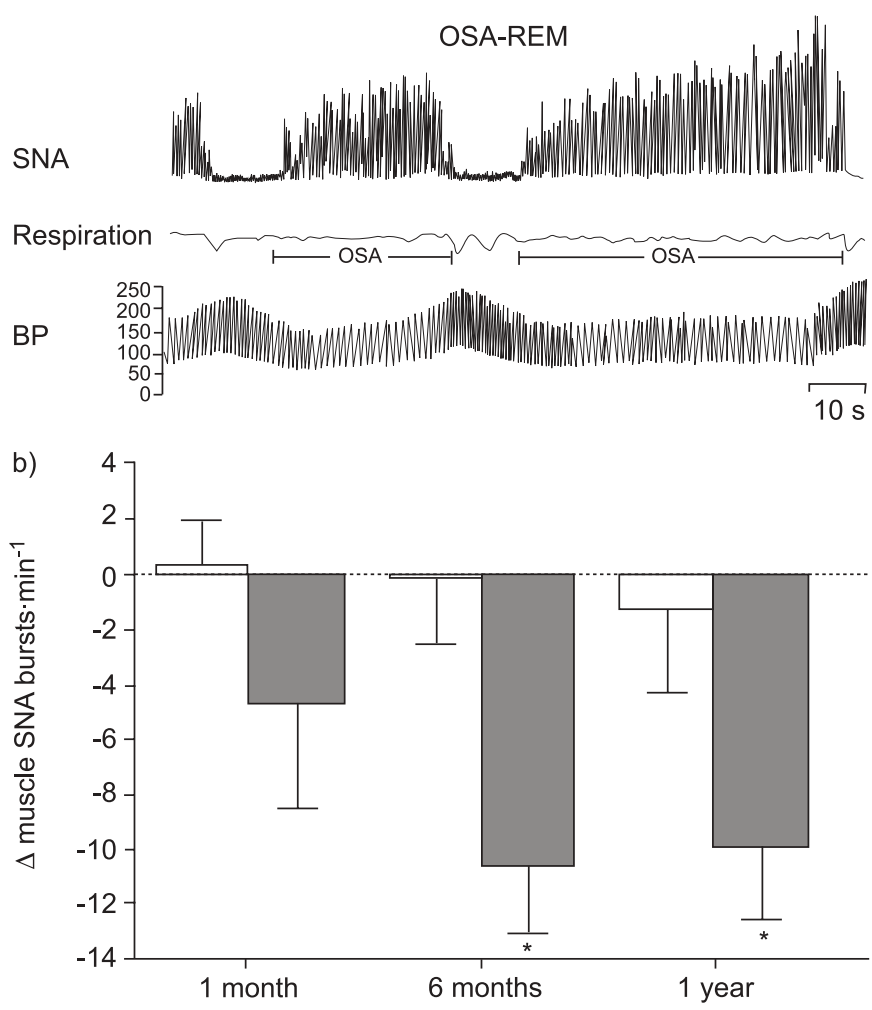

FIGURE 5. a) Recording of muscle sympathetic nerve activity (SNA), respiration and intra-arterial blood pressure (BP) in the same patient with obstructive sleep apnoea (OSA). When awake, muscle SNA is high and increases even further during each obstructive event and is accompanied by BP surges; continuous positive airway pressure (CPAP) is able to abolish the surges in muscle SNA and BP accompanying the apnoeic events. b) Repeated measurements of muscle SNA while awake demonstrated a significant decrease in OSA patients treated with CPAP after 6 months, still present after $1 \mathrm{yr}$; in nontreated OSA patients, no change was observed. $\square$ : untreated subjects; $\square$ : treated subjects. REM: rapid eye movement sleep. *: $p<0.05$. Reproduced from a) [37] and b) [39] with permission from the publishers.

of catabolic products [50-54]. In OSA patients, increased ROS production, namely increased free radical production by leukocytes, has been demonstrated. After starting CPAP, there is a rapid and long-lasting decrease of ROS release $[55,56]$. In addition, antioxidant activity is decreased in OSA patients [57, 58]. Plasma lipid peroxidation by free oxygen radicals has been observed in OSA patients and found to be reduced after CPAP $[58,59]$. These are important findings, as enhanced lipid peroxidation represents an important early step in the atherosclerotic process. In addition, more recently, DNA oxidation has also been detected [60].

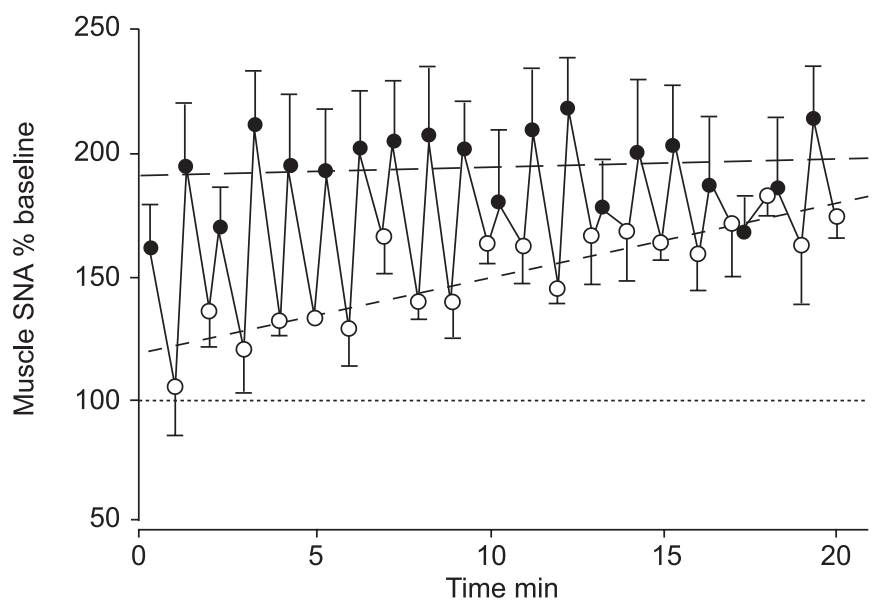

FIGURE 6. A hypercapnic hypoxic gas mixture was administered intermittently (20 s gas mixture $(\bullet), 40 \mathrm{~s}$ normoxia $(\bigcirc)$ ) to healthy subjects for $20 \mathrm{~min}$. Muscle sympathetic nerve activity (SNA) followed a cyclic crescendo-decrescendo pattern of asphyxia, but with each successive 40-s interasphyxia period, muscle SNA became progressively elevated, not returning to baseline $(\cdots \cdots) .---$ : $y=0.36 x+$ 190.36, $r=0.13, p=0.58 ;-\cdots: y=2.98 x+118.84, r=0.86, p<0.001$. Reproduced from [43] with permission from the publishers.

Increased oxidative stress can cause cell damage; however, ROS are also signalling molecules. It is now well established that ROS production is associated with the expression of specific genes, resulting in physiological and pathological consequences. The expression of these genes relies on activation of redox-sensitive signalling pathways and transcription factors. The most relevant redox-activated transcription factors in this context include the hypoxia-inducible factor (HIF)- $1 \alpha$, nuclear factor (NF)- $\mathrm{\kappa B}$ and activator protein (AP)-1. In response to hypoxia, HIF- $1 \alpha$ activates proteins adaptive to the sustained reduced oxygen availability, including proteins participating in angiogenesis, vascular reactivity and remodelling. Factors that may be involved in cardiovascular morbidity in OSA include vascular endothelial growth factor (VEGF), erythropoietin (regulating blood mass) and endothelin-1 (a potent vasoconstrictor and mitogenic peptide with blood pressure-elevating properties). Activation of NF- $\mathrm{\kappa B}$ and/or AP-1 results in the expression of a large number of cytokines and adhesion molecules. In a human cell culture model of intermittent hypoxia and re-oxygenation, RYAN et al. [61] identified a selective activation of inflammatory pathways, mediated by the transcription factor NF- $\mathrm{\kappa B}$ over adaptive HIF$1 \alpha$ (fig. 8). These results indicate a specific molecular response to intermittent hypoxia re-oxygenation that differs from the characteristic of sustained hypoxia, which is primarily mediated by HIF- $1 \alpha$. Several studies in OSA patients indirectly support these in vitro findings. In OSA, the increase of the HIF$1 \alpha$-induced proteins was either only moderate (VEGF) or the results were conflicting (erythropoietin, endothelin-1) [48]. However, marked upregulation of several protein products of the NF- $\kappa B$ transcription factor have been documented in OSA patients, including inflammatory cytokines, such as tumour necrosis factor- $\alpha$, interleukin- 6 and adhesion molecules. More details on the topic of inflammatory cytokines are covered in the articles by HARSCH [62] and BUYSE et al. [63] in the current 

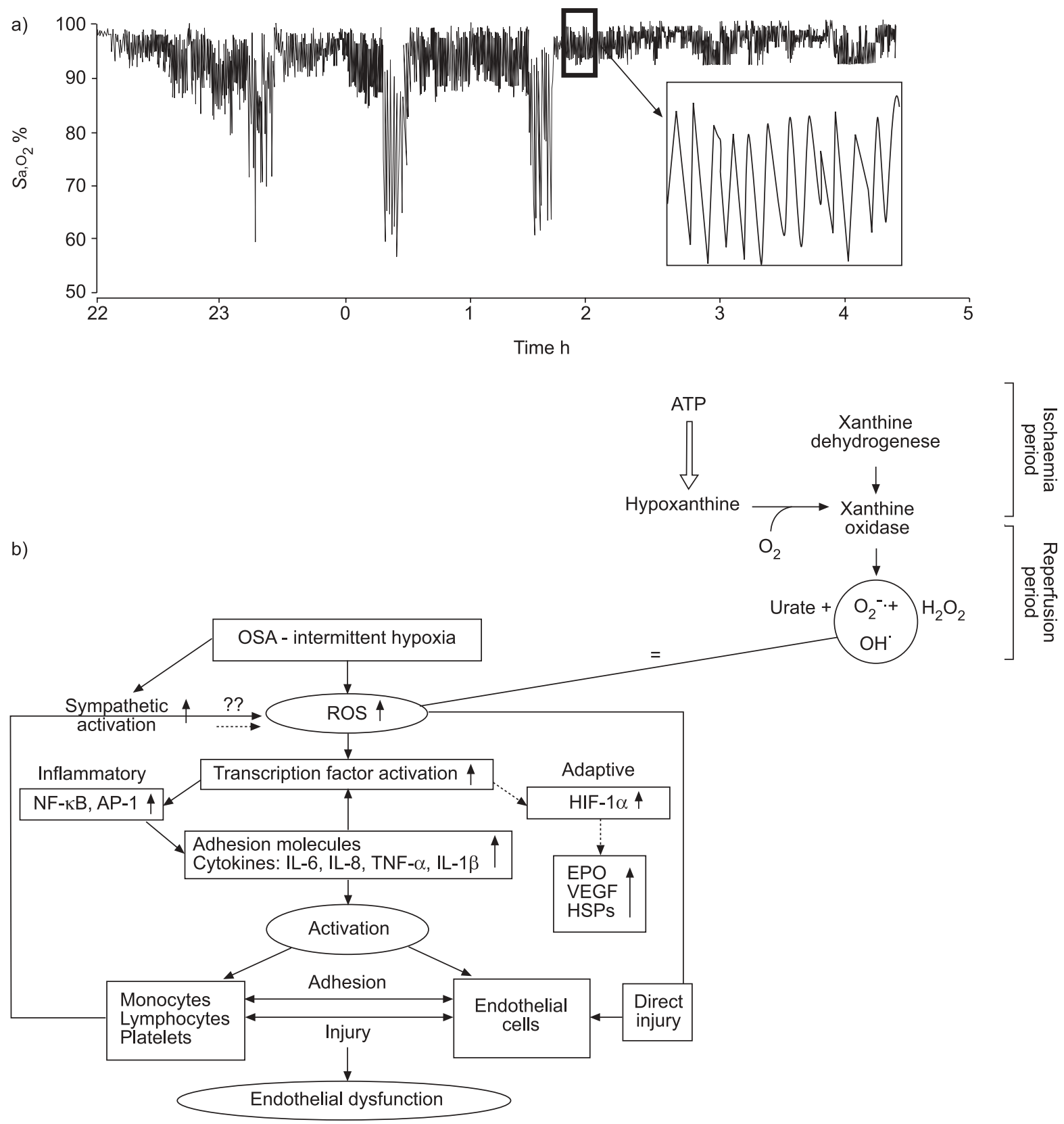

FIGURE 7. In obstructive sleep apnoea (OSA), a) the effects of drops in oxygen saturation $\left(\mathrm{Sa}, \mathrm{O}_{2}\right)$ lead to b) hypoxia-related formation of reactive oxygen species (ROS) This is a key mechanism in endothelial dysfunction and vascular disease. NF-kB: nuclear factor-kB; AP-1: activator protein-1; IL: interleukin; TNF: tumour necrosis factor; HIF: hypoxia-inducible factor; EPO: erythropoeitin; VEGF: vascular endothelial growth factor; HSP: heat shock protein. Modified from [48] with permission from the publishers.

issue of the ERR. Circulating levels of adhesion molecules (i.e. intercellular adhesion molecule-1 and vascular adhesion molecule-1) are found to be increased in patients with OSA compared with matched controls [64, 65]. More recently, expression of this type of adhesion molecule was determined in patients with coronary artery disease, either with or without concomitant OSA, in order to eliminate confounders, such as coronary artery disease itself [66]. The patients with coronary artery disease and OSA expressed higher concentrations of several adhesion molecules compared with those without OSA.

Dyugovkaya et al. [56] and LAvie et al. [67] have also demonstrated increased monocyte and lymphocyte activation, cytotoxicity and adherence to endothelial cells in OSA patients. Not only was intracellular monocyte ROS production increased, but there was also increased expression of monocytes of selectins exaggerating rolling and integrins, as well as exaggerated firm adhesion. After pre-treating endothelial cells with antibodies against selectins, the monocytes in the cultures of patients with OSA adhered significantly more avidly to endothelial cells than those of controls. The monocyte selectin upregulation in OSA was directly associated to the amount of hypoxia these patients experienced, as attested by the apnoea/hypopnoea severity dependence and by the increase of expression obtained after exposing monocytes of control subjects to hypoxia in vitro. More importantly, CPAP proportionally 


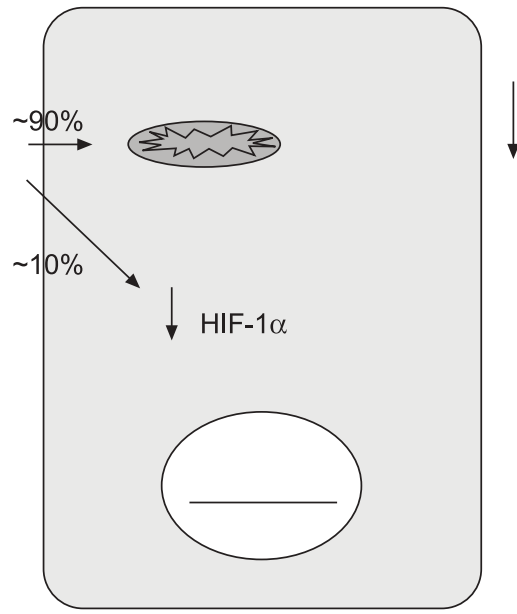

b)

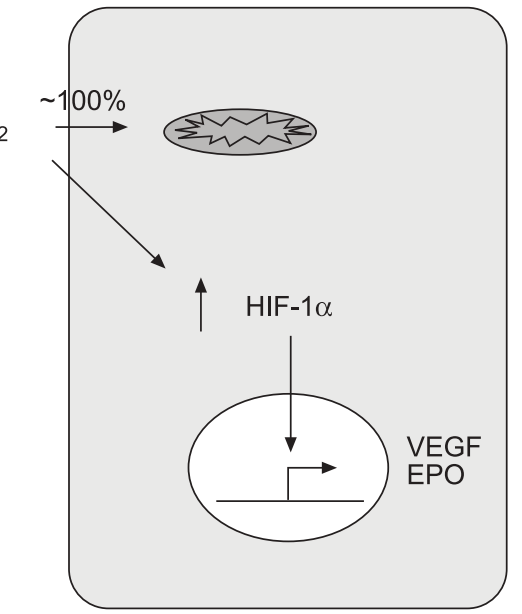

c)

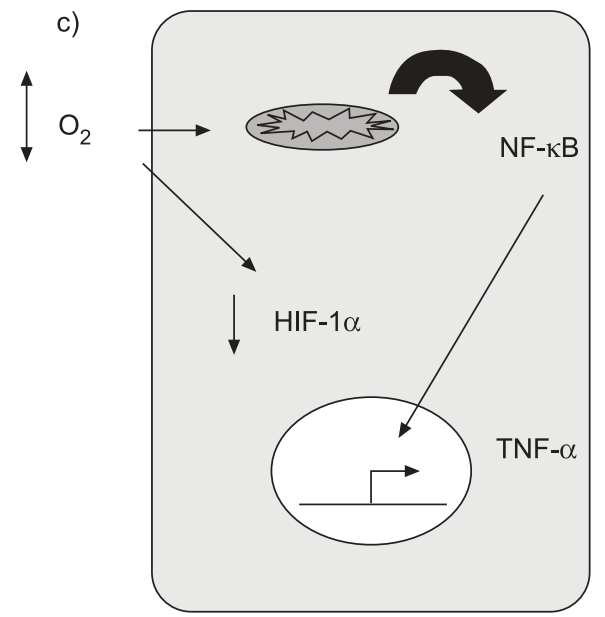

FIGURE 8. Schematic representations of a) sustained normoxia, b) sustained hypoxia and c) intermittent hypoxia. In human cell cultures, sustained hypoxia results in selective activation of adaptive mechanisms, while a model of intermittent hypoxia selectively activates the inflammatory pathways. HIF: hypoxia-inducible factor; VEGF: vascular endothelial growth factor; EPO: erythropoeitin; TNF: tumour necrosis factor; NF: nuclear factor. Reproduced from [61] with permission from the publishers.

reduced the expression of leukocyte selectin and integrin, decreased the ROS production of monocytes, and attenuated monocyte-endothelial cell interactions in culture.

LAVIE et al. [67] found not only hypoxia-related increased monocyte activation in patients with OSA, but also hypoxiainduced lymphocyte changes that might be of critical importance in the formation of atherosclerosis plaques. WEYAND et al. [68] clearly demonstrated that especially $\mathrm{T}$ lymphocyte cell immunity plays a significant role in plaque formation and in the development of acute coronary syndrome (upon activation, T-cells either differentiate into effector cells with tissue-damaging potential or secrete cytokines that may affect atherogenic pathways, such as macrophage activation, oxygen free radical production, adhesion molecule expression and smooth cell proliferation). DYOGOVASKA et al. [69-71] found that in OSA patients, $\gamma \delta$ T-cells, and CD4 and CD8 cells undergo functional changes and acquire cytotoxic capabilities against endothelial cells which could (in the case of CD4 and CD8) be reduced by CPAP treatment.

\section{Endothelial dysfunction/atherosclerosis}

The blood vessel has been characterised as a dynamic organ capable of sensing injury or changes in its surroundings, communicating such changes via intracellular signals, and to subsequently altering its structure [72]. In the vessel, there is a complex balance between vasoconstrictor vasoactive substances (which, in general, also induce cell growth) and vasodilators (which generally inhibit cell growth). Not only do these substances exert independent vascular effects, but they also reciprocally modulate actions. Injury of the endothelium results in disruption of the normal homeostatic balance of this system and this disruption results in endothelial dysfunction, which is considered to be the earliest manifestation of atherosclerosis. Endothelial injury can appear secondary to shear stress, as in the case of HT, but it may also result from excessive ROS production, such as that demonstrated to occur in OSA patients.
The functions of the vascular endothelium are complex and involve inhibition of platelet aggregation, modulation of leukocyte rolling, adhesion and transmigration, regulation of smooth muscle cell proliferation, and modulation of vascular wall contractility and permeability. However, in most cases, the term endothelial function is used as an equivalent to the ability of the endothelium to maintain the balance between vasodilatation and vasoconstriction [73].

Patients with OSA were first demonstrated to exhibit endothelial dysfunction on functional testing in small case control trials [74]. The Sleep Heart Health Study was the first population study to associate OSA with impaired flow mediated vasodilatation [75]. Several other publications on this topic have been found, but the present article will only report on those studies dealing with an interventional design (CPAP treatment).

IMADOJEMU et al. [76] detected that OSA patients had markedly reduced reactive hyperaemic forearm blood flow at baseline compared with nonapnoeic controls and found that reactive hyperaemic blood flow increased by $\sim 25 \%$ after CPAP therapy. Bradykinin is known to be able to activate nitric oxide synthase in endothelial cells leading to the generation of nitric oxide, a vasodilating agent [77]. DuCHNA et al. [78] used bradykinin and the forearm vasodilatation test in normotensive OSA patients versus nonapnoeic controls. There was a lower nitric oxide-dependent vasodilatation in the OSA group. Following 2 months of CPAP treatment, there was a return to the control levels. The degree of abnormality appeared to be related to the severity of hypoxaemia during sleep. In a further study from the same group [79], it was demonstrated that this recovery was still present after 6 months of regular CPAP use. IP et al. [80] studied males with and without OSA. Subjects with OSA had lower reactive hyperaemia than the controls (fig. 9a) and were randomised to either CPAP or observation for 4 weeks. There was a significant increase of reactive hyperaemia in the CPAP group, whereas those on observation had no change (fig. $9 \mathrm{~b}$ and $\mathrm{c}$ ). A group of 8 subjects who used CPAP for $>3$ months were reassessed upon short-term 
treatment withdrawal and the response to reactive hyperaemia again was similar to the baseline value (fig. 9d).

There are several studies focusing on typical biomarkers for endothelial dysfunction. Angiotensin has been demonstrated to act at a local "autocrine/paracrine" level within tissues. A distinct tissue angiotensin system is found in the central nervous system, heart, reproductive organs and, importantly, also in the vasculature [72]. In this system, angiotensin converting enzyme (ACE), predominantly present in the endothelium, plays a significant role. ACE regulates angiotensin II production and bradykinin. MoLLER et al. [81] measured $24 \mathrm{~h} \mathrm{BP}$ and plasma levels of vasoactive hormones (renin, angiotensin II, aldosterone, atrial natriuretic peptide, brain natriuretic peptide, vasopressin, and endothelin-1) in 24 patients with OSA and in 18 controls. As expected, the patients with OSA had higher BP levels without nocturnal dipping, and in these patients, higher circulating levels of angiotensin II and aldosterone were demonstrated. A positive correlation was also found between angiotensin II levels and daytime BP. BARCELO et al. [82] have also reported increased ACE activity in OSA patients. Several cardiovascular disorders have been linked to the presence of a specific insertion/deletion polymorphism of the ACE gene. In a recent study, LIN et al. [83] explored 1,100 subjects of the Wisconsin Sleep Cohort for the association between this insertion/deletion polymorphism and OSA/HT. OSA and the insertion/deletion polymorphism interacted significantly to modulate BP independently of age, sex, ethnicity and BMI. However, the authors hypothesised that in the absence of OSA, the effect of the deletion allele alone may not be sufficient to increase BP. Nitric oxide is another typical biomarker for endothelial dysfunction. Nitric oxide produces vascular smooth muscle relaxation and vasodilatation. It has been demonstrated that patients with OSA have decreased circulating levels of nitric oxide and, in addition, nitric oxide levels increased with the start of CPAP. The effect of CPAP was already obvious after the first night [84] and was still present at 5 months of follow-up [85].

Not only has endothelial dysfunction been demonstrated in OSA, but early structural signs of atherosclerosis have also been observed. Increased carotid artery intima thickness measured by ultrasonography, a method of evaluating atherosclerosis, is associated with an increased risk of stroke and cardiovascular disease. SUZUKI et al. [86] used this technique in patients without known cerebrovascular or cardiovascular
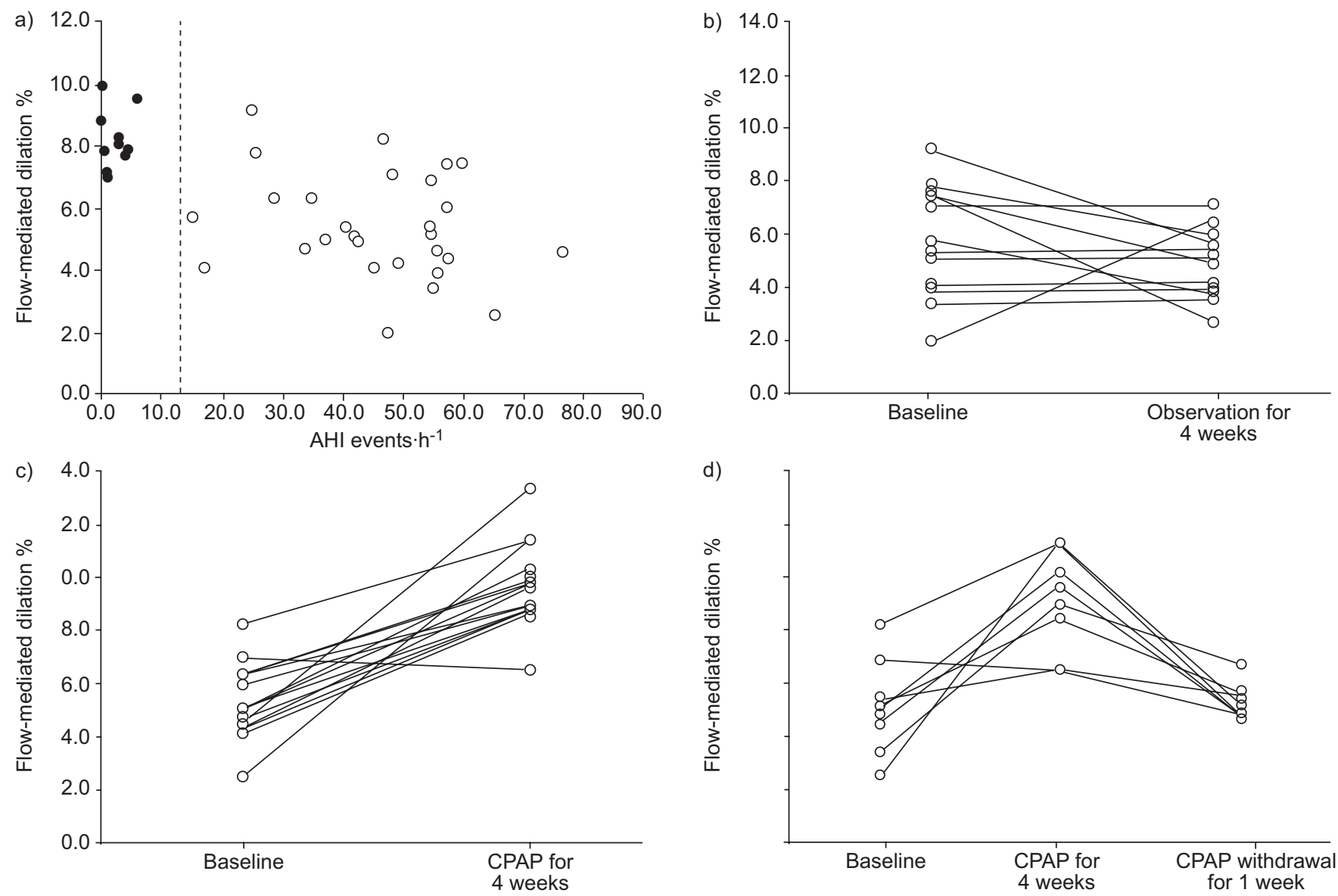

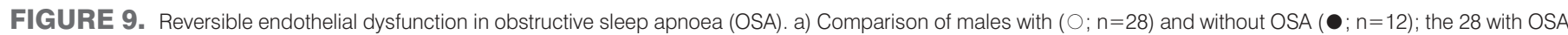

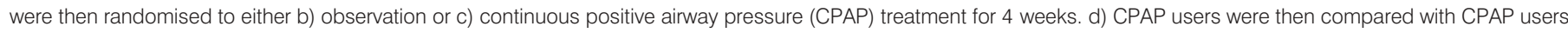
subjected to a 1-week withdrawal from CPAP. AHI: apnoea/hypopnoea index. Modified from [80] with permission from the publisher. 
disease, and demonstrated that the severity of OSA was independently (taking into account possible confounders, such as age, sex, obesity, hyperlipidaemia, hypertension, diabetes mellitus and smoking history) related to increased intima thickness or atherosclerosis. The same authors demonstrated that in this context, the severity of OSA-related hypoxaemia appeared to be more important than the frequency of the apnoea events. Their results have also been corroborated by others $[87,88]$.

In summary, a range of pathophysiological mechanisms have been proposed to explain the link between obstructive sleep apnoea and hypertension/vascular disease. Cyclic intermittent hypoxia is surely a key mechanism. On the one hand, these cyclic intermittent hypoxic events during sleep increase the peripheral chemoreflex sensitivity, which is accompanied by a sustained increase in sympathetic neural activity and blood pressure; on the other hand, hypoxia re-oxygenation-related formation of free radicals is an early key trigger of vascular inflammation, endothelial dysfunction and atherosclerosis. However, several other mechanisms should be considered (e.g. the impact of angiotensin activation, especially at the local vascular level and the role of different gene polymorphisms) and surely merit further investigation. Some other mechanisms include the following; 1) the increased ability of platelets to aggregate, which is observed in patients with obstructive sleep apnoea, and the observation that abolition of obstructive sleep apnoea by continuous positive airway pressure therapy results in reduced ability of platelets to aggregate. This aspect is in part explained by sympathetic overactivity [89-91]; 2) the leptin and insulin resistance problem that appears to be common in obstructive sleep apnoea subjects (again, this resistance may, at least in part, be induced by sympathetic overactivity); and 3) the role of the baroreceptor and baroreceptor adaptation.

\section{APPENDIX}

Working group 2. France: I. Arnulf (Paris), S. Launois-Rollinat, P. Lévy (Grenoble); Germany: H. Becker (Marburg), T. Penzel, (Berlin), I. Harsch (Erlangen), L. Lüthje (Göttingen); Sweden: L. Grote, J. Hedner, (Gothenburg); Belgium: E. Hamans (Antwerp), R. Poirrier (Liège), K. Spiegel, (Brussels); USA: S. Javaheri (Mason, OH); Israel: L. Lavie, P. Lavie (Haïfa); Finland: T. Saaresranta (Turku); UK: I. Smith (Cambridge), E. Verstraeten (Swansea), P. Turkington (Salford).

The present article was presented as part of the international symposium "Respiratory somnology: a clinical update", sponsored by GlaxoSmithKline, Belgium. T. Penzel has received reimbursement for conference attendance and speaker fees from Respironics and Weinmann. L. Grote has received research funding from Breas Medical AB, ResMed, Respironics, Weinmann, Itamar Medical Ltd and Pfizer. L. Grote has also received speaker and educational fees from ResMed, Respironics, Weinmann and Pfizer. S. Javaheri has acted as a consultant for, and received honoraria for lectures and research from, Respironics and ResMed. P. Lavie is a founder and board member of Itamar Medical Ltd, SLP Ltd, Sleep Health Centers US and Sleep Disorders Center Israel; he owns options and shares in these companies. I. Smith has received travel grants and honoraria from Cephalon, UK. His research staff have been funded by unrestricted educational grants from ResMed and Friday Medical Ltd. I. Arnulf has received speaker fees from Cephalon Ltd.

\section{REFERENCES}

1 Javaheri S. Treatment of obstructive and central sleep apnoea in heart failure: practical options. Eur Respir Rev 2007; 16: 183-188.

2 Lavie P. Mortality in sleep apnoea syndrome: a review of the evidence. Eur Respir Rev 2007; 16: 203-210.

3 Pack AI. Advances in sleep-disordered breathing. Am J Respir Crit Care Med 2006; 173: 7-15.

4 Nieto FJ, Young TB, Lind BK, et al. Association of sleepdisordered breathing, sleep apnea, and hypertension in a large community-based study. JAMA 2000; 283; 1829-1836.

5 Young T, Peppard PE, Palta M, et al. Population-based study of sleep-disordered breathing as a risk factor for hypertension. Arch Intern Med 1997; 157: 1746-1752.

6 Peppard PE, Young T, Palta M, Skatrud J. Prospective study of the association between sleep-disordered breathing and hypertension. $N$ Engl J Med 2000; 342: 1378-1384.

7 Brooks D, Horner RL, Kozar LF, Render-Teixeira CL, Phillipson EA. Obstructive sleep apnoea as a cause of systemic hypertension. Evidence from a canine model. J Clin Invest 1997; 99: 106-109.

8 Engleman HM, Gough K, Martin SE, Kingshott RN, Padfield PL, Douglas NJ. Ambulatory blood pressure on and off continuous positive airway pressure therapy for the sleep apnea/hypopnea syndrome: effects in "nondippers". Sleep 1996; 19: 378-381.

9 Dimsdale J, Loredo JS, Profant J. Effect of continuous positive airway pressure on blood pressure. A placebo trial. Hypertension 2000; 35: 144-147.

10 Barbé F, Mayorolas LR, Duran J, et al. Treatment with continuous positive airway pressure is not effective in patients with sleep apnea but no daytime sleepiness. Ann Intern Med 2001; 134: 1015-1023.

11 Monasterio C, Vidal S, Duran J, et al. Effectiveness of continuous positive airway pressure in mild sleep apneahypopnea syndrome. Am J Respir Crit Care Med 2001; 164: 939-943.

12 Faccenda JF, Mackay ThW, Boon NA, Douglas NJ., Randomized placebo-controlled trial of continuous positive airway pressure on blood pressure in the sleep apneahypopnea syndrome. Am J Respir Crit Care Med 2001; 163: 344-348.

13 Barnes M, Houston D, Worsnop CJ, et al. A randomized controlled trial of continuous positive airway pressure in mild obstructive sleep apnea. Am J Respir Crit Care Med 2002; 165: 773-780.

14 Pepperell JCT, Ramdassingh-Dow S, Crosthwaite N, et al. Ambulatory blood pressure after therapeutic and subtherapeutic nasal continuous positive airway pressure for obstructive sleep apnoea: a randomised parallel trial. Lancet 2002; 359: 204-210.

15 Becker HF, Jerrentrup A, Ploch $\mathrm{T}$, et al. Effect of nasal continuous positive airway pressure treatment on blood pressure in patients with obstructive sleep apnea. Circulation 2003; 107: 68-73. 
16 Mills PJ, Kennedy BP, Loredo JS, Dimsdale JE, Ziegler MG. Effects of nasal continuous positive airway pressure and oxygen supplementation on norepinephrine kinetics and cardiovascular responses in obstructive sleep apnea. J Appl Physiol 2006; 100: 343-348.

17 Norman D, Loredo JS, Nelesen RA, et al. Effects of continuous positive airway pressure versus supplemental oxygen on 24-hour ambulatory blood pressure. Hypertension 2006; 47: 840-845.

18 Campos-Rodriguez F, Grilo-Reina A, Perez-Ronchel J, et al. Effects of continuous positive airway pressure on ambulatory BP in patients with sleep apnea and hypertension. Chest 2006; 129: 1459-1467.

19 Robinson GV, Smith DM, Langford SA, Davies RJO, Stradling JR. Continuous positive airway pressure does not reduce blood pressure in nonsleepy hypertensive OSA patients. Eur Respir J 2006; 27: 1229-1235.

20 MacMahon S, Peto R, Cutler J, et al. Blood pressure, stroke and coronary heart disease. Part 1, prolonged differences in blood pressure: prospective observational studies corrected for the regression dilution bias. Lancet 1990; 335: 765-774.

21 Weichler U, Herres Mayer B, Mayer J, Weber K, Hoffmann R, Peter JH. Influence of antihypertensive drug therapy on sleep pattern and sleep apnea activity. Cardiology 1991; 78: 124-130.

22 Kantola I, Rauhala E, Erkinjuntti M, Mansury L. Sleep disturbances in hypertension: a double-blind study between isradipine and metoprolol. I Cardiovasc Pharmacol 1991; 18: Suppl. 3, S41-S45.

23 Pelttari L, Rauhala E, Kantola I. Effects of antihypertensive medication on hypertension in patients with sleep apnoea. Blood Press Suppl 1994; 2: 88-91.

24 Pelltari L, Hietanen EK, Salo TT, Kataja MJ, Kantola IM. Little effect of ordinary antihypertensive therapy on nocturnal high blood pressure in patients with sleep disordered breathing. Am J Hypert 1998; 1: 272-279.

25 Kraiczi H, Hedner J, Peker Y, Grote L. Comparison of atenolol, amlodipine, enalapril, hydrochlorothiazide, and losartan for antihypertensive treatment in patients with obstructive sleep apnea. Am J Respir Crit Care Med 2000; 161: 1423-1428.

26 Shahar E, Whitney C, Redline S, et al. Sleep-disordered breathing and cardiovascular disease: cross-sectional results of the Sleep Heart Health Study. Am J Respir Crit Care Med 2001; 163: 19-25.

27 Artz M, Young T, Finn L, Skatrud JB, Bradley TD. Association of sleep-disordered breathing and the occurrence of stroke. Am J Respir Crit Care Med 2005; 172: 14471451.

28 Yaggi HK, Concato J, Kernan WN, Lichtman JH, Brass LM, Mohsenin V. Obstructive sleep apnea as a risk factor for stroke and death. New Engl J Med 2005; 353: 2034-2041.

29 Peker Y, Hedner J, Kraiczi H, Löth S. Respiratory disturbance index: an independent predictor of mortality in coronary artery disease. Am J Respir Crit Care Med 2000; 162: 181-186.

30 Mooe T, Franklin KA, Holmstrom K, Rabben T, Wiklund U. Sleep-disordered breathing and coronary artery disease: long-term prognosis. Am J Respir Crit Care Med 2001; 164: 1910-1913.
31 Milleron O, Pilliere R, Foucher A, et al. Benefits of obstructive sleep apnoea treatment in coronary artery disease; a long-term follow-up study. Eur Heart J 2004; 25: 729-734.

32 Stradling J. Con: sleep apnea does not cause cardiovascular disease. Am J Respir Crit Care Med 2004; 169: 148-149.

33 Fletcher EC, Miller J, Schaaf JW, Fletcher JG. Urinary catecholamines before and after tracheostomy in patients with obstructive sleep apnoea and hypertension. Sleep 1987; 10: 35-44.

34 Ziegler MG, Mills PJ, Loredo JS, Ancoli-Israel S, Dimsdale JE. Effect of continuous positive airway pressure and placebo treatment on sympathetic nervous activity in patients with obstructive sleep apnea. Chest 2001; 120: 887893.

35 Hedner J, Ejnell H, Sellgren J, Hedner T, Wallin G. Is high and fluctuating muscle nerve sympathetic activity in the sleep apnea syndrome of pathogenetic importance for the development of hypertension? J Hypertension Suppl 1988; 6: S529-S531.

36 Carlson JT, Hedner J, Elam M, Ejnell H, Sellgren J, Wallin BF. Augmented resting sympathetic activity in awake patients with obstructive sleep apnea. Chest 1993; 103: 1763-1768.

37 Somers VK, Dyken ME, Clary MP, Abboud FM. Sympathetic neural mechanisms in obstructive sleep apnea. J Clin Invest 1995; 96: 1897-1904.

38 Waradekar NV, Sinoway LI, Zwillich CW, Leuenberger UA. Influence of treatment on muscle sympathetic nerve activity in sleep apnea. Am J Respir Crit Care Med 1996; 153: 1333-1338.

39 Narkiewicz K, Masahiko K, Phillips BG, Pesek CA, Davidson DE, Somers VK. Nocturnal CPAP decreases daytime sympathetic traffic in OSA. Circulation 1999; 100: 2332-2335.

40 Morgan BJ, Crabtree DC, Puleo DS, Badr MS, Toiber F, Skatrud JB. Neurocirculatory consequences of abrupt change in sleep state in humans. J Appl Physiol 1996; 80: 1627-1636.

41 Leuenberger U, Jacob E, Sweet L, Waravdekar N, Zwillich C, Sinoway L. Surges of muscle sympathetic nerve activity during obstructive apnea linked to hypoxemia. J Appl Physiol 1995; 79: 581-588.

42 Narkiewicz K, van de Borne PJ, Montano N, Dyken ME, Phillips BG, Somers VK. Contribution of tonic chemoreflex activation to sympathetic activity and blood pressure in patients with obstructive sleep apnea. Circulation 1998; 97: 943-945.

43 Xie J, Skatrud JB, Crabtree DC, Boodman BM, Morgan BJ. Neurocirculatory consequences of intermittent asphyxia in humans. J Appl Physiol 2000; 89: 1333-1339.

44 Hedner JA, Wilcox I, Laks L, Grunstein RR, Sullivan CE. A specific and potent effect of hypoxia in patients with sleep apnea. Am Rev Respir Dis 1992; 146: 1420-1245.

45 Narkiewicz K, van de Borne PJ, Pesek CA, Dyken ME, Montano N, Somers VK. Selective potentiation of peripheral chemoreflex sensitivity in obstructive sleep apnea. Circulation 1999; 99: 1183-1189.

46 Tun Y, Hida W, Okabe S, et al. Effects of nasal continuous positive airway pressure on awake ventilatory response to 
hypoxia and hypercapnia in patients with obstructive sleep apnea. Tohoku J Exp Med 2000; 190: 157-168.

47 Börgel J, Schulz T, Bartels NK, et al. Modifying effects of the R389G $\beta 1$-adrenorecpetor polymorphism on resting heart rate and blood pressure in patients with obstructive sleep apnoea. Clin Sci 2006; 110: 117-123.

48 Lavie L. Obstructive sleep apnoea syndrome - an oxidative stress disorder. Sleep Med Rev 2003; 7: 35-51.

49 Dean RT, Wilcox I. Possible atherogenic effects of hypoxia during obstructive sleep apnea. Sleep 1993; 16: Suppl. 8, S15-S22.

50 Findley LJ, Boykin M, Fallon T, Belardinelli L. Plasma adenosine and hypoxaemia in patients with sleep apnea. $J$ Appl Physiol 1988; 64: 556-561.

51 Hasday JD, Grum CM. Nocturnal increase of urinary uric acid: creatinine ratio. A biochemical correlate of sleepassociated hypoxaemia. Am Rev Respir Dis 1987; 135: 534538.

52 McKeon JL, Saunders NA, Murree-Allen K. Urinary uric acid: creatinine ratio, serum erythropoietin, and blood 2,3-diphosphoglycerate in patients with obstructive sleep apnea. Am Rev Respir Dis 1990; 142: 8-13.

53 Braghiroli A, Sacco C, Erbetta M. Overnight urinary uric acid: creatinine ratio for detection of sleep hypoxaemia. Validation study in chronic obstructive pulmonary disease and obstructive sleep apnea before and after treatment with nasal continuous positive airway pressure. Am Rev Respir Dis 1993; 148: 173-178.

54 Sahebjani H. Changes in urinary uric acid excretion in obstructive sleep apnea before and after therapy with nasal continuous positive airway pressure. Chest 1998; 113: 16041608.

55 Shultz R, Mahmoudi S, Hattar K, et al. Enhanced release of superoxide from polymorphonuclear neutrophils in obstructive sleep apnea. Impact of continuous positive airway pressure therapy. Am J Respir Crit Care Med 2000; 162: 566-470.

56 Dyugovkaya L, Lavie P, Lavie L. Increased adhesion molecules expression and production of reactive oxygen species in leukocytes of sleep apnea patients. Am J Respir Crit Care Med 2002; 165: 934-939.

57 Lavie L, Vishnesky A, Lavie P. Evidence for lipid peroxidation in obstructive sleep apnea. Sleep 2004; 27: 123-128.

58 Christou K, Markoulis N, Moulas AN, Pestuka AN, Gourgoulionis KI. Reactive oxygen metabolites (ROMs) as an index of oxidative stress in obstructive sleep apnea patients. Sleep Breath 2003; 7: 105-110.

59 Barcelo A, Miralles C, Barbé F, Vila M, Pons S, Agusti AGN. Abnormal lipid peroxidation in patients with sleep apnea. Eur Respir J 2000; 16: 644-647.

60 Yamauchi M, Nakano H, Maekawa J, et al. Oxidative stress in obstructive sleep apnea. Chest 2005; 127: 1674-1679.

61 Ryan S, Taylor CT, McNicholas WT. Selective activation of inflammatory pathways by intermittent hypoxia in obstructive sleep apnea syndrome. Circulation 2005; 112: 2660-2667.

62 Harsch IA. Metabolic disturbances in patients with obstructive sleep apnoea syndrome. Eur Respir Rev 2007; 16: 196-202.
63 Buyse B, the participants of working group 2. Treatment effects of sleep apnoea: where are we now? Eur Respir Rev 2007; 16: 146-168.

64 Chin K, Nakamura T, Shimuzi K, et al. Effects of nasal continuous positive airway pressure on soluble cell adhesion molecules in patients with obstructive sleep apnea syndrome. Am J Med 2000; 109: 562-567.

65 Ohga E, Nagase T, Tomita T, et al. Increased levels of circulating ICAM-1, VCAM-1 and L-selectin in obstructive sleep apnea syndrome. J Appl Physiol 1999; 87: 10-14.

66 El-Sohl AA, Mador MJ, Sikka P, Raiwinder RS, Amsterdam D, Grant BJB. Adhesion molecules in patients with coronary artery disease and moderate-to-severe obstructive sleep apnea. Chest 2002; 121: 1541-1547.

67 Lavie L, Dyogovskaya L, Lavie P. Sleep apnea related intermittent hypoxia and atherogenesis: adhesion molecules and monocytes/endothelial cells interactions. Atherosclerosis 2005; 183: 183-184.

68 Weyand CM, Goronzy JJ, Liuzzo G, Kopecky SL, Holmes DR Jr, Frye RL. T-cell immunity in acute coronary syndromes. Mayo Clin Proc 2001; 76: 1011-1020.

69 Dyugovskaya L, Lavie P, Lavie L. Phenotypic and functional characterization of blood gammadelta $\mathrm{T}$ cells in sleep apnea. Am J Respir Crit Care Med 2003; 168: 242-249.

70 Dyugovskaya L, Lavie P, Hirsh M, Lavie L. Activated CD8+ T-lymphocytes in obstructive sleep apnoea. Eur Respir J 2005; 25: 820-828.

71 Dyugovskaya L, Lavie P, Lavie L. Lymphocyte activation as a possible measure of atherosclerotic risk in patients with sleep apnea. Ann NY Acad Sci 2005; 1051: 340-350.

72 Gibbons GH. Endothelial function as a determinant of vascular function and structure: a new therapeutic target. Am J Cardiol 1997; 79: 3-8.

73 Deanfield J, Donald A, Ferri Cl, et al, Endothelial function and dysfunction. Part I: methodological issues for assessment in the different vascular beds: A statement by the working group on endothelin and endothelial factors of the European Society of Hypertension. J Hypertens 2005; 23: 7-17.

74 Carlson J, Rångemark C, Hedner J. Attenuated endothelium-dependent vascular relaxation in patients with sleep apnea. J Hypertension 1996; 14: 577-584.

75 Nieto FJ, Heerington DM, Redline S, Benjamin EJ, Robbins JA. Sleep apnea and markers of vascular endothelial function in a large community sample of older adults. Am J Respir Crit Care Med 2004; 169: 354-360.

76 Imadojemu VA, Gleeson K, Quraishi SA, Kunselman A, Sinoway LI, Leuenberger UA. Impaired vasodilator responses in obstructive sleep apnea are improved with continuous positive airway pressure therapy. Am J Respir Crit Care Med 2002; 165: 950-953.

77 Palmer RM, Ashton DS, Moncada S. Vascular endothelial cells synthesize nitric oxide from L-arginine. Nature 1988; 333: 664-666.

78 Duchna HW, Guilleminault Ch, Stoohs R, et al. Vascular reactivity in obstructive sleep apnea syndrome. Am J Respir Crit Care Med 2000; 161: 187-191.

79 Duchna HW, Orth M, Schultze-Werninghaus G, Guilleminault $\mathrm{Ch}$, Stoohs RA. Long-term effects of nasal continuous positive airway pressure on vasodilatory 
endothelial function in obstructive sleep apnea syndrome. Sleep Breath 2005; 9: 97-103.

80 Ip MSM, Tse H-F, Lam B, Tsang KW, Lam W-K. Endothelial function in obstructive sleep apnea and response to treatment. Am J Respir Crit Care Med 2004; 169: 348-353.

81 Moller DS, Lind P, Strunge B, Pedersen EB. Abnormal vasoactive hormones and 24-hour blood pressure in obstructive sleep apnea. Am J Hypertens 2003; 274-280.

82 Barcelo A, Elorza MA, Barbé F, Santos C, Mayoralas LR, Agusti AGN. Angiotensin converting enzyme in patients with sleep apnoea syndrome: plasma activity and gene polymorphisms. Eur Respir J 2001; 17: 728-732.

83 Lin L, Finn L, Zhang J, Young T, Mignot E. Angiotensinconverting enzyme, sleep-disordered breathing, and hypertension. Am J Respir Crit Care Med 2004; 170: 13491353.

84 Ip MSM, Lam B, Chan L-Y, et al. Circulating nitric oxide is suppressed in obstructive sleep apnea and is reversed by nasal continuous positive airway pressure. Am J Respir Crit Care Med 2000; 162: 2166-2171.

85 Schulz R, Schmidt D, Blum A, et al. Decreased plasma levels of nitric oxide derivates in obstructive sleep apnoea; response to CPAP therapy. Thorax 2000; 55: 1046-1051.

86 Suzuki T, Nakano H, Maekawa J, et al. Obstructive sleep apnea and carotid-artery intima-media thickness. Sleep 2004; 27: 129-133.

87 Minoguchi K, Yokoe T, Tazaki T, et al. Increased carotid intima-media thickness and serum inflammatory markers in obstructive sleep apnea. Am J Respir Crit Care Med 2005; 172: 625-630.

88 Drager LF, Bortolotto LA, Lorenzi MC, Figuereido AC, Krieger EM, Lorenzi-Filho G. Early signs of atherosclerosis in obstructive sleep apnea. Am J Respir Crit Care Med 2005; 172: 613-618.

89 Sanner BM, Konermann M, Tepel M, et al. Platelet function in patients with obstructive sleep apnoea syndrome. Eur Respir J 2000; 16: 648-652.

90 Eisensehr I, Ehrenberg BL, Noachtar S, et al. Platelet activation, epinephrine, and blood pressure in obstructive sleep apnea syndrome. Neurology 1998; 51: 188-195.

91 Bobinsky G, Miller M, Ault K, Husband P, Mitchell J. Spontaneous platelet activation and aggregation during obstructive sleep apnea and its response to therapy with nasal continuous positive airway pressure: a preliminary investigation. Chest 1995; 108: 625-630. 